International Journal of Current Advanced Research

ISSN: O: 2319-6475, ISSN: P: 2319 - 6505, Impact Factor: SJIF: 5.995

Available Online at www.journalijcar.org

Volume 6; Issue 4; April 2017; Page No. 3229-3232

DOI: http://dx.doi.org/10.24327/ijcar.2017.3232.0232

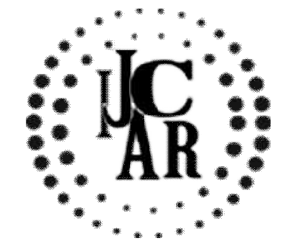

Review Article

\title{
GENETIC MARKERS IN TYPE II DIABETES MELLITUS AMONG INDIAN POPULATION-A REVIEW
}

\section{Sandra Sagar* and Kannan Rajendran}

Department of General Medicine, Saveetha Medical College and Hospitals, Saveetha University, Chennai, Tamilnadu, India

\begin{tabular}{l}
\hline A R T I C L E I N F O \\
Article History: \\
Received $19^{\text {th }}$ January, 2017 \\
Received in revised form $18^{\text {th }}$ February, 2017 \\
Accepted $22^{\text {nd }}$ March, 2017 \\
Published online $28^{\text {th }}$ April, 2017 \\
\end{tabular}

Key words:

Type II DM, genes, genetic markers.

\begin{abstract}
A B S T R A C T
Present review is written to relate the various genetic markers in type II Diabetes Mellitus (DM) among Indian population. Genes play a vital role in the development of Diabetes Mellitus. Type II diabetes is often a polygenic disorder with multiple genes located on different chromosomes being associated with this condition which include environmental factors which also contribute to the clinical manifestation of the disorder in genetically predisposed persons. Only a minority of cases of type II diabetes are caused by single gene defects such as maturity onset diabetes of the young (MODY), syndrome of insulin resistance (insulin receptor defect) and maternally inherited diabetes and deafness (mitochondrial gene defect). According to WHO, India leads the world with largest number of Diabetic patients. Reports from several Indian population studies give a heterogeneous picture owing to its diverse ethnicity. The major issue to address in diabetes biology is to identify the genetic changes in the disease and their occurrence in different populations. So the review is done to correlate and understand the various genes involved in type II Diabetes Mellitus in Indian Population.
\end{abstract}

Copyright $(2017$ Sandra Sagar and Kannan Rajendran. This is an open access article distributed under the Creative Commons Attribution License, which permits unrestricted use, distribution, and reproduction in any medium, provided the original work is properly cited.

\section{INTRODUCTION}

Diabetes refers to a group of metabolic diseases characterized by hyperglycemia resulting from defects in insulin secretion, insulin action, or both [1]. The chronic hyperglycemia of diabetes is associated with long-term damage, dysfunction, and failure of different organs, especially the eyes, kidneys, nerves, heart, and blood vessels. Diabetes is currently the fastest-growing epidemic and has been ascribed to a collision between genes and the environment.India and China have the highest reported prevalences of diabetes. More than $90 \%$ of these cases are considered as T2D making T2D the fastestincreasing disease worldwide [2, 3]. The T2D epidemic can largely be ascribed to the worldwide increase in obesity during the last 30 years. [4]. This has been ascribed to a collision between genes and the environment. The social determinants of environmental factors tend to vary across populations and have changed rapidly over the last decades. A traditional high energy-burning lifestyle has been replaced by a Western sedentary lifestyle with little or no exercise and consumption of an energy-dense diet. Meanwhile, genetic factors evolve at a slower rate across generations, and tend to favor selection of "energy-saving thrifty genotypes," which might have been beneficial for individuals living in times of unstable food supply by storing energy in times of surplus [5].

\section{*Corresponding author: Sandra Sagar}

Department of General Medicine, Saveetha Medical College and Hospitals, Saveetha University,
Genes play a vital role in the development of Diabetes Mellitus.Type II DM is a polygenic disorder with multiple genes located on different chromosomes resulting in this condition. The major issue to address in Diabetes biology is to identify the genetic changes in the disease and their occurrence in different populations.Until recently, type 2 diabetes was typically regarded as a disease of the middleaged and elderly. Though this age-group maintains a higher risk than younger adults, evidence is accumulating that even children and adolescents aged less than 30 years are now becoming caught up in the diabetes epidemic, which has mainly been attributed to the high level of obesity in these groups. The decrease in the age of onset of diabetes is of great concern as future generations may be burdened with morbidity and mortality at the height of their productivity, potentially affecting the workforce and healthcare resources of the countries across the world. So the present review is written with a view to summarise the various genetic markers involved in typeII Diabetes Mellitus among South Indian Population.

\section{Role of Genes in Type Ii Dm}

It has long been known that T2D is, in part, inherited. Family studies have revealed that first degree relatives of individuals with T2D are about 3 times more likely to develop the disease than individuals without a positive family history of the disease. T2D has a strong genetic component.[6] 
UPPAR (peroxisome proliferator-activated receptor- $\gamma$ ) $U$. This gene has been widely studied because it is important in adipocyte and lipid metabolism. In addition, it is a target for the hypoglycemic drugs known as thiazolidinediones. One form of the PPAR $\gamma$ gene (Pro) decreases insulin sensitivity and increases T2D risk by several fold. Perhaps more importantly is that this variant is very common in most populations[7]

UABCC8 (ATP binding cassette, subfamily $C$, member 8) U. This gene encodes the high-affinity sulfonylurea receptor (SUR1) subunit that is coupled to the Kir6.2 subunit (encoded by UKCNJ11U, also known as the potassium channel, inwardly rectifying subfamily $\mathrm{J}$, member 11). Both genes are part of the ATP-sensitive potassium channel, which plays a key role in regulating the release of hormones, such as insulin and glucagon, in the beta cell. Mutations in either gene can affect the potassiumchannel's activity and insulin secretion, ultimately leading to the development of T2D. Interestingly, ABCC8 and KCNJ11 are only $4.5 \mathrm{~kb}$ apart, and not far from the INS gene. Variant forms of KCNJ11 (Lys) and ABCC8 (Ala) genes have been associated with $\mathrm{T} 2 \mathrm{D}$, as well as other diabetes-related traits. Because of the close proximity of these genes, current studies are evaluating whether they work in concert with each other, or rather have an independent effect on T2D susceptibility.

Since PPAR $\gamma, \mathrm{ABCC} 8$ and KCNJ11 are the targets of drugs used routinely in the treatment of $T 2 \mathrm{D}$, there are pharmacogenetic implications for maintaining good glycemic control. Response to hypoglycemic therapy may actually be related one's genotype. Thus, genetic testing may not only help determine who is at high risk for developing T2D, but may also be useful in guiding treatment regimens for T2D. [8]

UCAPN10 (calpain 10)U. CAPN10 encodes an intracellular calcium-dependent cysteine protease that is ubiquitously expressed (Cox et al., 2004). A haplotype that was initially linked to T2D included an intronic $A$ to $G$ mutation at position 43, which appears to be involved in CAPN10 transcription. Two amino acid polymorphisms (Thr504Ala and Phe200Thr) have also been associated with T2D risk. However, it has been suggested that the coding and noncoding polymorphisms do not independently influence T2D risk, but instead contribute to an earlier age at diagnosis. Physiological studies suggest that variations in calpain 10 activity effects insulin secretion, and therefore, susceptibility to T2D.

UHNF4A (hepatocyte nuclear factor 4- $\alpha$ ) $\boldsymbol{U}$. Mutations in promoter and coding regions of the HNF4A gene cause MODY1. HNF4A is expressed in many tissues, including the liver and pancreas. It regulates hepatic gene expression, and influences the expression of other MODY genes such as HNF1A, which causes MODY3. In the beta cell of the pancreas, it directly activates insulin gene expression. Mutations in the HNF4A gene also have been associated with T2D.

UHNF1A (hepatocyte nucleara factor 1-a) U. MODY3, the most frequent cause of the disease, results from mutations in the HNF1A gene. HNF1A is expressed in the liver and pancreas. It can also influence HNF4A expression, indicating a connection between MODY1 and MODY3. This suggests that the MODY transcription factors form a regulatory network that maintains glucose homeostasis. In addition to causing MODY3, HNF1A mutations have been associated with T1D and T2D.[9]

UIPF1 (insulin promoter factor-1)U. MODY4, which is a rare form of the disease, is due to mutations in the IPF1 gene. Homozygosity for such mutations has been associated with newborn pancreatic agenesis and neonatal diabetes. Therefore, infants who carry MODY4 mutations tend to be small for gestational age. Individuals with MODY4 may also develop T2D .IPF1 regulates expression of glucokinase, insulin and other genes involved in glucose metabolism.

UHNF1B (hepatocyte nucleara factor 1- $\beta$ ) U. MODY5, another rare form of MODY, has also been linked with MODY1 because HNF1 $\beta$ regulates HNF4 $\alpha$. However, unlike MODY1, MODY5 is also associated with renal cysts, proteinuria and renal failure.

UNEUROD1 (neurogenic differentiation factor 1)U. Mutations in NEUROD1 are responsible for MODY6. MODY6 is also rare. Together, MODY4, MODY5 and MODY6 comprise less then $3 \%$ of all MODY cases. NERUOD1 is expressed in the beta cells of the pancreas, the intestine and the brain. In the pancreas, it contributes to the regulation of the expression of insulin. [10]

\section{Genetic Markers among Indian Population}

In Asian Indians, the D1057D genotype of insulin receptor substrate 2 (IRS-2) gene is susceptible to diabetes by interacting with obesity [11]. Association of lipoprotein lipase Hind III (T-G) and Ser447Thr (C- G) polymorphism with dyslipidemia has been studied in Asian Indians by Radha et al., [12] and it was shown that $\mathrm{H}+$ Ser and $\mathrm{H}$-Ter were the 'high- risk' and 'low-risk' haplotypes for low HDL cholesterol and elevated triglyceride levels respectively. It has also been shown that -T93G SNP of lipoprotein lipase gene is associated with obesity but not T2D, whereas the - G53C SNP appears to be protective against both obesity and T2D[13]. A few studies in North western Indian Punjabi populations show association of apolipoprotein E (APOE) (Hha1), angiotensin-1 converting enzyme (ACE) I/D, APOA1-CIIIAIV gene cluster with lipid levels in T2D and CHD [14] and Paraoxonase (PON1) activity to CAD and T2D [15]. Studies in North Indians show genetic association of interleukin-1 beta $(-511 \mathrm{C} / \mathrm{T})$ and interleukin-1 receptor antagonist $(86 \mathrm{bp}$ repeat) polymorphism with T2D [16]. Thr394Thr (G-A) polymorphism of peroxisome proliferator activated receptorco-activator-1 alpha (PGC-1 alpha) gene has been shown to be associated with T2D in Asian Indian subjects and also with total, visceral and subcutaneous body fat[17]. Two North Indian populations showed significant association of PGC-1 alpha variants (Thr394Thr \& Gly482Ser) with T2D[18] Analysis of mitochondrial G10398A/T16189C haplotypic combinations suggests susceptibility of these alleles to T2D independently as well as together [19]. A comparison of risk genotype combinations of uncoupling protein-2 (UCP2) 866GG, mtDNA 10398A and PGC1 alpha p.Thr394Thr or p.Gly482Ser against the protective genotypes UCP2- 866XA, mtDNA 10398G and PGC1 alpha p.Thr394Thr or PGC1 alpha p.Gly482Ser showed a highly significant difference and increased ORs, showing significance of additive interaction of multiple small effects of the studied candidate gene variations in a complex disease like T2D. Among all the association studies with T2D in Indian populations, TCF7L2 has been shown to be most promising in South Indian [20]and Western 
Indian [21],[22]populations, where intronic SNP (rs12255372, rs7903146, rs4506565) show association with T2D[23] have also replicated association of eight well established genetic variants with T2D in North Western Indian populations showing higher effect size compared to the Europeans.

\section{Genes and Environmental Interactions}

Gene interactions, or epistasis, have been suggested as a possible explanation for difficulties in replicating genetic association in complex diseases [24]. The standard statistical methods used in association studies are usually limited to analysis of single marker effects and thereby do not account for interactions between markers. Previous attempts to study epistasis in complex diseases have focused on interactions between candidate regions [25,26]. However, the recent abundance of GWAS data has made a comprehensive search across the genome more feasible. Some studies have attempted to account for epistasis in GWAS using a two-step approach in which significant SNPs are tested against each other or against all other SNPs in the study with variable results $[27,28]$. The main problem when studying epistasis is power, since interaction between loci with modest effects is difficult to detect without extremely large sample sizes. However, some studies have pointed at novel tests to increase power [29]. Thorough studies in diabetes addressing epistasis using this approach are missing. Furthermore, a recent paper by Eric Lander and co-workers provided compelling evidence that gene-gene interaction can also contribute to missing heritability by causing "phantom heritability" that inflates the estimated narrow sense heritability of the trait [30]. Gene and environment interactions are equally difficult to study but are likely to play an important role in T2D development. The epidemic of T2D only dates back 50 years, and it is quite obvious that during this period that only the environment, and not the genes, have changed. However, the genetic architecture determines our response to the environment. Genetic variants could affect specific metabolic processes to make an individual more susceptible to the harmful effects of a poor diet but also personality traits that make an individual more or less likely to over-consume and live a sedentary lifestyle. It will however be a formidable task to identify the environmental triggers for most of the genetic variants increasing susceptibility to diabetes as this will require very large studies with precise information on diet, exercise, energy expenditure, etc.

\section{CONCLUSION}

The genetic revolution has allowed identification of numerous genetic variants that associate with T2D. The genetic landscape of T2D susceptibility is as yet incomplete, thus far only explaining a small proportion of the total heritability of diabetes. It has already greatly contributed to our understanding of disease mechanisms by identifying pathways that could not be linked to diabetes by existing hypothetical models, even though many genetic findings are very recent and have yet to make their contribution to our knowledge about diabetes pathogenesis. However, one must bear in mind that diabetes is probably a much more diverse disease than the current subdivision into T1D and T2D implies and more precise subdivision into subgroups may both facilitate the investigation of T2D genetics and pave the way for more individualized treatment. A holistic systems biology approach will also be required to obtain a complete picture of how genetic variation leads to diabetes.

\section{References}

1. Groop, L.; Lyssenko, V. Genetics of type 2 diabetes. An overview. Endocrinol. Nutr. 2009, 56 (Suppl. 4), 34-37. Genes 2015, 6111

2. Diabetes Atlas, 2014. Available online: www.Idf.Org/diabetesatlas (accessed on 3 March 2014).

3. WHO. WHO report. 2014. Available online: http://www.who.int/gho/publications/world_health_ statistics/en/ (accessed on 3 March 2014).

4. Lyssenko, V.; Jonsson, A.; Almgren, P.; Pulizzi, N.; Isomaa, B.; Tuomi, T.; Berglund, G.; Altshuler, D.; Nilsson, P.; Groop, L. Clinical risk factors, DNA variants, and the development of type 2 diabetes. N. Engl. J. Med. 2008, 359, 2220-2232.

5. Groop, L. Pathogenesis of type 2 diabetes: The relative contribution of insulin resistance and impaired insulin secretion. Int. J. Clin. Pract. Suppl. 2000, 113, 3-13.

6. Shepherd, M., Hattersley, A.T. 'I don't feel like a diabetic any more': the impact of stopping insulin in patients with maturity onset diabetes of the young following genetic testing. Clin Med, 2004. 4: 144-147. 60. Silander, K., Mohlke, K.L., Scott, L.J., et al. Genetic variation near the hepatocyte nuclear factor-4a gene predicts susceptibility to type 2 diabetes. Diabetes, 2004. 53: 1141-1149.

7. Sinha, R., Fisch, G., Teague, B., et al. Prevalence of impaired glucose tolerance among children and adolescents with marked obesity. N Engl J Med, 2002. 346: 802-810.

8. Sobngwi, E., Boudou, P., Mauvais-Jarvis, F., et al. Effect of a diabetic environment in utero on predisposition to type 2 diabetes. Lancet, 2003. 361: 1861-1865. 63. Stride, A., Hattersley, A.T. Different genes, different diabetes: lessons from maturity-onset diabetes of the young. Ann Med, 2002. 34: 207-216.

9. Lehto, M., Wipemo, C., Ivarsson, S.A., et al. High frequency of mutations in MODY and mitochondrial genes in Scandinavian patients with familial earlyonset diabetes. Diabetologia, 1999. 42: 1131-1137

10. Fagot-Campagna, A., Pettitt, D.J., Engelgau, M.M., et al. Type 2 diabetes among North American children and adolescents: an epidemiologic review and a public health perspective. J Pediatr, 2000. 136: 664-672.

11. Bodhini D, Radha V, Deepa R, Ghosh S, Majumder PP, Rao MRS, et al. (2007). The G1057D polymorphism of IRS-2 gene and its relationship with obesity in conferring susceptibility to type 2 diabetes in Asian Indians. Int J Obesity 3:97-102.

12. Radha V, Mohan V, Vidya R, Ashok AK, Deepa R, Mathias RA (2006). Association of lipoprotein lipase Hind III and Ser 447 Ter polymorphisms with dyslipidemia in Asian Indians. Am J Cardiol 97:133742.

13. Radha V, Vimaleswaran KS, Babu HNS, Abate N, Chandalia M, Sathija P, et al. (2006). Role of genetic polymorphism peroxisome proliferator- activated receptor gamma2- Pro12Ala on ethnic susceptibility to diabetes in South-Asian and Caucasian subjects. Diabetes Care 29:1046-51. 
14. Singh P, Singh M, Gaur S, Kaur T (2007). The ApoAICIII-AIV gene cluster and its relation to lipid levels in type 2 diabetes mellitus and coronary heart disease: determination of a novel susceptible haplotype. DiabVasc Dis Res 4: 124-9.

15. Singh PP, Naz I, Gilmour A, Singh M, Mastana S (2006). Association of APOE (Hha1) and ACE (I/D) gene polymorphisms with type 2 diabetes mellitus in North West India. Diabetes Res ClinPract 74:95-102.

16. Achyut BR, Srivastava A, Bhattacharya S, Mittal B (2007). Genetic association of interleukin- 1beta $(-511 \mathrm{C} / \mathrm{T})$ and interleukin-1 receptor antagonist (86 bp repeat) polymorphisms with Type 2 diabetes mellitus in North Indians. ClinChimActa 377:163-9.

17. Vimaleswaran KS, Radha V, Anjana M, Deepa R, Ghosh S, Majumder PP, et al. (2006). Effect of polymorphisms in the PPARGC1A gene on body fat in Asian Indians. Int J Obesity 30: 884-91.

18. Bhatt A, Koul A, Rai E, Sharma S, Dhar MK, Bamezai RN (2007). PGC-1 alpha Thr394Thr and Gly482Ser variants are significantly associated with T2DM in two North Indian populations: a replicate case-control study. Hum Genet. 121:609-14.

19. Bhatt A, Koul A, Sharma S, Rai E, Bukhari SI, Dhar MK, Bamezai RN (2007). The possible role of 10398A and $16189 \mathrm{C}$ mtDNA variants in providing susceptibility to T2DM in two North Indian populations: a replicative study. Hum Genet. 120:8216.

20. Bottcher Y, Korner A, Reinehr T, Enigk B, Kiess W, StumvollM,Kovacs P (2006). ENPP1 variants and haplotypes predispose to early onset obesity and impaired glucose and insulin metabolism in German obese children. J ClinEndocrinolMetab 91:4948-52.

21. Chandak GR, Janipalli CS, Bhaskar S, Kulkarni SR, Mohana Krishna P, Hattersley AT, Frayling TM, Yajnik CS (2007). Common variants in the TCF7L2 gene are strongly associated with type 2 diabetes mellitus in the Indian population. Diabetologia 50:637.
22. Chandalia M, Abate N, Garg A, Stray-Gunderson J, Grundy SM (1999). Relationship between generalized and upper body obesity to insulin resistance in Asian Indian men. J ClinEndocrinolMetab 84: 2329-35.

23. Chauhan G, Spurgeon CJ, Tabassum R, Bhaskar S, Kulkarni SR, Mahajan A et al. (2010). Impact of common variants of PPARG, KCNJ11, TCF7L2, SLC30A8, HHEX, CDKN2A, IGF2BP2, and CDKAL1 on the risk of type 2 diabetes in 5,164 Indians. Diabetes 59: 2068-2074.

24. Phillips, P.C. Epistasis-The essential role of gene interactions in the structure and evolution of genetic systems. Nat. Rev. Genet. 2008, 9, 855-867.

25. Cordell, H.J.; Wedig, G.C.; Jacobs, K.B.; Elston, R.C. Multilocus linkage tests based on affected relative pairs. Am. J. Hum. Genet. 2000, 66, 1273-1286.

26. Cox, N.J.; Frigge, M.; Nicolae, D.L.; Concannon, P.; Hanis, C.L.; Bell, G.I.; Kong, A. Loci on chromosomes 2 (niddm1) and 15 interact to increase susceptibility to diabetes in Mexican Americans. Nat. Genet. 1999, 21, 213-215.

27. Gonzalez-Perez, A.; Gayan, J.; Marin, J.; Galan, J.J.; Saez, M.E.; Real, L.M.; Antunez, C.; Ruiz, A. Wholegenome conditional two-locus analysis identifies novel candidate genes for late-onset parkinson's disease. Neurogenetics 2009, 10, 173-181.

28. Nair, R.P.; Duffin, K.C.; Helms, C.; Ding, J.; Stuart, P.E.; Goldgar, D.; Gudjonsson, J.E.; Li, Y.; Tejasvi, T.; Feng, B.J.; et al. Genome-wide scan reveals association of psoriasis with il-23 and nf-kappab pathways. Nat. Genet. 2009, 41, 199-204.

29. Evans, D.M.; Marchini, J.; Morris, A.P.; Cardon, L.R. Two-stage two-locus models in genome-wide association. PLOS Genet. 2006, 2, e157.

30. Zuk, O.; Hechter, E.; Sunyaev, S.R.; Lander, E.S. The mystery of missing heritability: Genetic interactions create phantom heritability. Proc. Natl. Acad. Sci. USA 2012, 109, 1193-1198.

\section{How to cite this article:}

Sandra Sagar and Kannan Rajendran (2017) ' Genetic Markers In Type Ii Diabetes Mellitus Among Indian Population-A Review', International Journal of Current Advanced Research, 06(04), pp. 3229-3232.

DOI: http://dx.doi.org/10.24327/ijcar.2017.3232.0232 